\title{
Development of safety management technology of electric power networks in order to sustainable development
}

\author{
Vyacheslav Burlov1 [0000-0001-7603-9786], Maxim Polyukhovich ${ }^{1 *}$ [0000-0003-2722-5552], Viktor

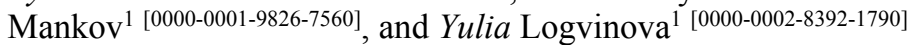 \\ ${ }^{1}$ Peter the Great St. Petersburg Polytechnic University, Polytechnicheskaya st., 29, St. Petersburg, \\ Russia
}

\begin{abstract}
One of the fundamental principles of sustainable development is sustainable electric power supply to consumers. The implementation of this principle is possible only with guaranteed safety of electric power networks. Forecasting of possible threats is one of the tools to reduce the fault rate of technological equipment. Emergency shutdowns are largely caused by meteorological factors. The instability of meteorological conditions can lead to significant negative consequences for human life and activities. For forecasting and diagnosing meteorological conditions, it is advisable to use a territorial geo information system (GIS). Safety management processes requires the process creation with predefined properties. For safety management, it is recommended to use synthesisbased models, which makes it possible to apply an approach based on solving the inverse management problem. As a result of the study, the safety management technology of electric power networks based on the use of GIS was developed. The research considers threats caused by the impact of meteorological factors. In particular, some problems arising under the influence on the control object of environmental temperature, wind, and thunderstorm were analyzed. The presented simulation of safety management processes allows to guarantee reliable and safe electric power supply to consumers.
\end{abstract}

Keywords: electric power network, safety management system, geo information system, human decision model.

\section{Introduction}

One of the key sectors of the global economy is electric power industry. Therefore, it is necessary to ensure high-quality transmission of electricity to consumers for the sustainable development of human society.

Reliability of electric power supply is mainly characterized by the number of power outages associated with the operation of the main equipment of electric power networks [1]. Because of an emergency shutdown, there is a lack of electrical energy, which leads to disruption of the functioning of technological processes of various objects of the economy.

${ }^{*}$ Corresponding author: mpolyukhovich@gmail.com 
Ensuring of safety of electric power networks guarantees their proper performance [2]. Operational safety depends on the equipment, maintaining it in operational condition, organizing a prompt service system, drawing an electric power network that excludes extraneous effect. The convenience of operating the electric power networks is specified by the level of technical aesthetics and ergonomics of the equipment reliability, the use of advanced techniques and labor methods that prevent erroneous and unqualified actions of staff, the use of maintenance-free and low-maintenance equipment [3-4].

Management of the stable functioning of electric power networks implies the solution of the following main tasks:

- ensuring the technological and infrastructural function of the electric power network on condition of equal opportunities for its use by all consumers of electricity [5];

- ensuring stable and safe operation of the equipment of electric power networks, reliable electric power supply to consumers and the quality of electricity in accordance with the requirements of regulatory acts;

- ensuring contractual stipulations for the electric power supply to consumers [6];

- minimization of electric power networks technical constraints within economically feasible limits;

- reduction of transmission and distribution costs of electricity due to the implementation of advanced technologies for maintenance and repair of electrical equipment, new equipment and energy conservation measures [7].

Electric power supply is characterized by reliability and quality. The concept of quality primarily refers to the quality of electricity, which is affected by various disturbances and distortions of the shape of the supply voltage.

Electric power supply problems arise in the following cases:

- power line congestion [8];

- short circuit or lightning strike;

- presence in the supply line of industrial and domestic electrical appliances with large pulsed energy consumption;

- defective wiring in the building;

- outage of electrical substation equipment or its malfunction [9];

- power line break.

Thus, the problem of developing a model for managing the safety of the electric power supply process arises.

The complex of managerial, organizational and technical measures should be aimed at improving the reliability of electric power supply and ensuring the safety of employees of operating organizations, consumers and the population. Forecasting of possible threats is one of the tools to reduce the fault rate of technological equipment [10-11].

The instability of meteorological conditions can lead to significant negative consequences for human life and activities [12-13]. For forecasting and diagnosing meteorological conditions, it is advisable to use a territorial geo information system (GIS) [14-16], which will make it possible to make a timely and accurate forecast of environmental conditions. GIS for operational monitoring of the environment includes an integrated set of technologies for collecting, storing and processing data, means of information received, and computer tools for implementing algorithms and models of objects / phenomena [17-19]. Furthermore, the practicability of the use of GIS for forecasting meteorological conditions is due to the possibility of collecting and processing long-term data on the environment. 


\section{Methods}

Safety management processes requires the process creation with predefined properties [20]. When developing a system for forecasting possible threats to the functioning of electric power networks, it is necessary to consider the following models of the functioning of two processes:

1. The process of functioning of electric power networks.

2. The process of forecasting of meteorological factors.

The basis of any human activity is the decision of a person. Decision maker (DM) acts on the basis of a model [20]. To ensure the safety of the operation of electric power networks, it is necessary to have an adequate mathematical model of human solutions.

The dependence on the meteorological conditions of failures of the structural components of electric power networks and the complexity of the process of forecasting the frequencies of incidents determine the urgency of developing a safety management technology of electric power networks based on the use of GIS.

\subsection{General approach to safety process of electric power networks}

The person in the human activity deals with four processes:

1. The target process (electric power supply to consumers).

2. The process of problem manifestation.

3. The process of problem identification.

4. The process of problem neutralization.

Sustainable functioning of any object is impossible without the organization of its protection, which includes a set of measures aimed at identifying the main threats and dangerous situations, assessing damage in the implementation of these threats [21-22], and creating an object safety management system. This paper discusses the threats arising from the impact of meteorological factors on the object of study.

For safety management, it is recommended to use synthesis-based models [23], which makes it possible to apply an approach based on solving the inverse management problem.

For the synthesis, the natural-scientific approach [20] is applied, based the object integrity maintenance law (OIML) [23].

The results of the application of the OIML are intended to theoretically substantiate the use of a set of measures that ensure safety and maintain the effectiveness of the operation of the control object.

As the decision is the basis of human activity, it is necessary to form a managerial decision to ensure safety.

To form an adequate model of managerial decision, it is necessary to decompose the concept of «Managerial decision» into three basic elements: «Situation», «Info-analytic work» and actually «Decision» (Fig. 1). 


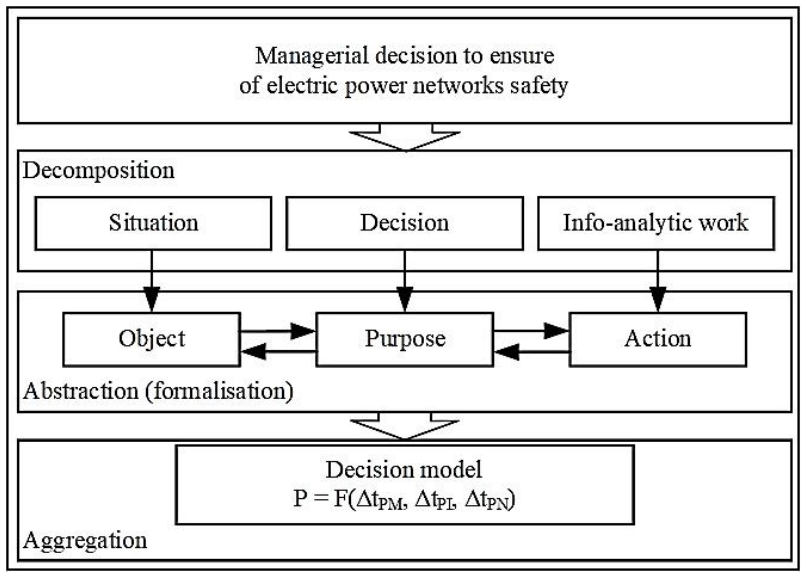

Fig. 1. The structural scheme of formalization of managerial decision.

At the first level, the decomposition method is applied - the solution is divided into three elements: «situation», «decision» and «info-analytic work», which correspond to «object», «purpose» and «action».

At the second level, abstraction method is applied. A person perceives facts correlated in time, therefore it is advisable to characterize the «situation» («object») by the average time the problem manifestation before the person $-\Delta t_{P M}$. «Purpose» («Decision») is identified with the frequency of the problem neutralization (the average time of an adequate response to the problem) by a person $-\Delta t_{P N}$. «Action» («Info-analytic work») is identified with the frequency of the problem identification (average time to recognize the situation) $\Delta t_{P I}$. It is accepted that these time intervals are random variables, and the following diagram is used of the change in the basic components of the formation of the solution model (Fig. 2 (a) the average time of problem manifestation; b) average time of problem identification; c) average time of problem neutralization; d) average time to complete the target (supply of electricity to consumers)) [23].

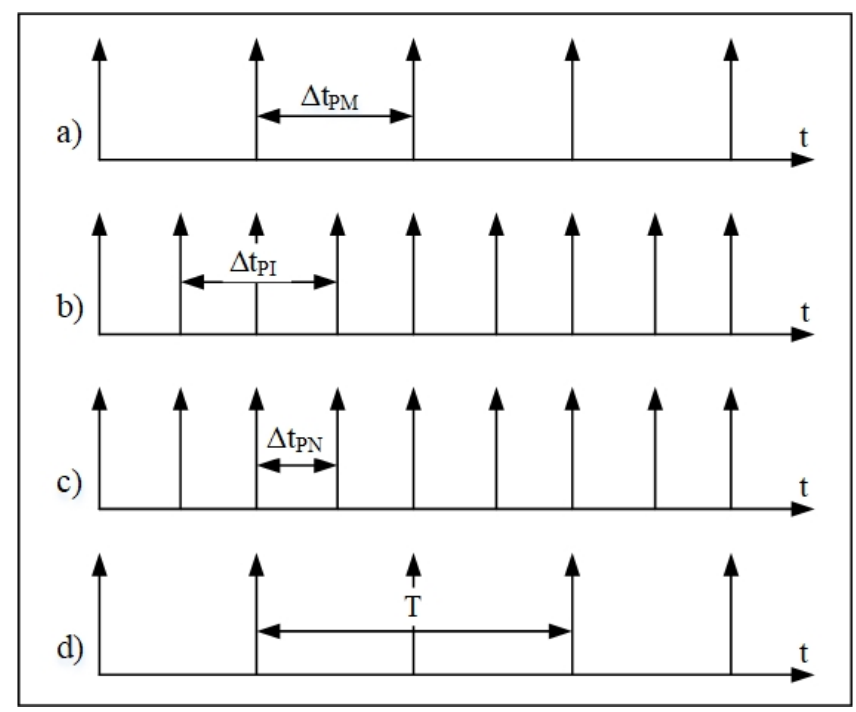

Fig. 2. The manifestation of the basic elements of the formation of the decision model. 
Then at the third level, the aggregation method is implemented, and an aggregate is created - a mathematical solution model (basic regularity) [23]:

$$
P=F\left(\Delta t_{P M}, \Delta t_{P I}, \Delta t_{P N}, T, \zeta^{-}\right),
$$

where $\zeta^{-}$frequency of disruption of the fulfillment of the purpose task (electric power supply to consumers).

Thus, the equation (1) is a condition for the existence of a process of safety management of electric power networks.

\subsection{Criterion for guaranteed safety management of electric power network}

In the [23], a state graph of the process of formation of a managerial decision was developed, and the following equation was obtained:

$$
P_{I N P}=\frac{\zeta^{+} v_{1} v_{2}+\lambda v_{1} v_{2}}{\lambda \zeta^{-} v_{1}+\lambda \zeta^{-} v_{2}+\zeta^{+} v_{1} v_{2}+\lambda v_{1} v_{2}+\zeta^{-} v_{1} v_{2}}
$$

where $\lambda$ - the inverse value of the average time the manifestation of the problem; $v_{1}-$ the inverse value of the average time the identification of the problem; $v_{2}-$ the inverse value of the average time the neutralization of the problem; $\zeta^{+}-$the inverse value of the average time to complete the purpose task (characterization of the degree of preparedness for solving management tasks); $\zeta^{-}-$value characterizing the average frequency of the purpose task.

Equation (2) is a condition for the existence of a process of safety management of electric power networks.

\subsection{State graph analysis}

To establish the functional dependences of the intensities of the target process, the flow of problems, the identification and the neutralization of disruptions, and the time of duration of transitions in the safety management of electric power network, the structural-functional method is used. This approach allows to evaluate through the critical path the time of duration $\Delta t_{P M}, \Delta t_{P I}, \Delta t_{P N}$.

To determine the indicator of the effectiveness of the functioning of the safety management system of electric power network, it is necessary to analyze the network models of three processes: the manifestation of a problem, the identification of a problem, and the neutralization of a problem.

The analysis of the network model is necessary to identify the reserves of time of task, which situated on noncritical paths. The identified reserves are directed to operation processes that situated on a critical path, and that, in turn, limits the deadline for completing work as a whole. Thus, it is possible to achieve a reduction in the execution time of critical task, and, therefore, the entire operation.

The main parameters of the network model are the time for completion of tasks and temporary reserves, which are presented below.

1. Earliest possible time of the $j$ th event $T_{P}(j)$ is calculated by equation (3).

$$
T_{P}(j)=\max _{i \subset j}\left(T_{P}(i)+t_{i j}\right),
$$

where the symbols $i$ and $j$ denote the previous and subsequent event numbers, respectively; $t_{i j}-$ duration of transition of the $(i, j)$ th operating process. The notation $i \subset j$ indicates that event $i$ precedes event $j$.

2. The latest acceptable time of the $i$ th event $T_{A}(i)$ is calculated by equation (4). 


$$
T_{A}(i)=\min _{i \supset j}\left(T_{A}(j)-t_{i j}\right)
$$

3. The time reserve of event $R_{i}$ is calculated by equation (5).

$$
R_{i}=T_{A}(i)-T_{P}(i)
$$

4. Full reserve of operation time $r_{i j}^{A}$ is calculated by (6).

$$
r_{i j}^{A}=T_{A}(j)-T_{P}(i)-t_{i j}
$$

The meaning of the full reserve of operation time is that a delay in the execution of work (i, j) by an amount $\Delta t_{i j}>r_{i j}^{A}$ leads to a delay in the occurrence of the final event by an amount $\left[\Delta t_{i j}-r_{i j}^{A}\right]$.

The duration of the critical path of the process is calculated as the sum of the duration of works for which the total time reserves are zero.

\section{Results}

The following threats may arise during the operation of an electric power system:

- technical and technological nature threats (deterioration of electric wires, power line congestion, outage of electrical substation equipment or its malfunction, etc.);

- social nature threats (terrorist acts, sabotage attacks unlawful acts, etc.);

- economic nature threats.

Because of the implementation of these threats, the electric power supply to consumers lays off and dangerous zones for humans arise.

In this research some of the threats caused by meteorological factors are mentioned. It should be noted that the given time intervals are determined on the basis of expert analysis, in reality, these values may differ. For example, they depend on the location area of the object, the state of the protective zones of electric power networks, the season, etc.

It is assumed that the purpose task (electric power supply to consumers) is carried out within a month ( $\mathrm{T}-30$ days, the month of June)), and the average frequency of nonfulfillment of the purpose task does not exceed $10 \%$.

Fig. 3 shows a network model of the manifestation of a problem caused by the influence of meteorological factors during the operation of electric power networks (the name of the transition is stamped over the line, the transition duration in minutes is indicated at the bottom of the line).

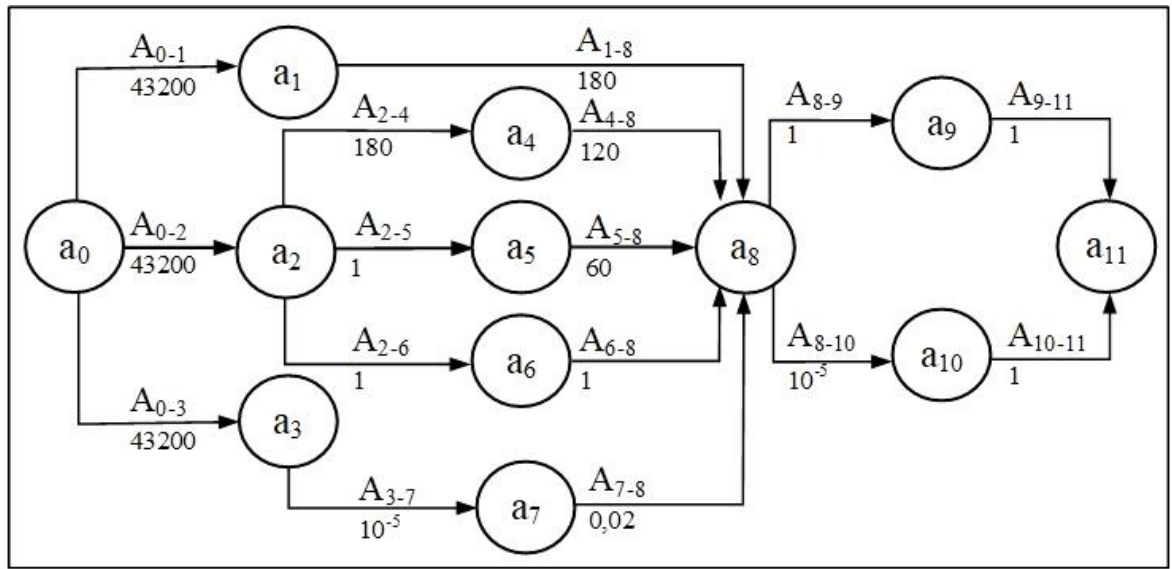

Fig. 3. Network model of the manifestation of a problem caused by the impact of meteorological factors during the operation of electric power system. 
In the table 1 the list of events of the network model of the process of the manifestation of the problem are shown, indicating their earliest possible time, the latest acceptable time, and time reserve.

Table 1. Events on the manifestation of the problems caused by the impact of meteorological factors during the operation of electric power network.

\begin{tabular}{|c|l|c|c|c|}
\hline $\begin{array}{c}\text { Designations } \\
\text { of events }\end{array}$ & $\begin{array}{l}\text { Name of the } \text { th event of the process } \\
\text { of manifestation of the problem }\end{array}$ & $T_{P}(j)$ & $T_{A}(i)$ & $R_{i}$ \\
\hline $\mathrm{a}_{0}$ & $\begin{array}{l}\text { Threat factor formation } \\
\text { (meteorological factor impact) }\end{array}$ & 0 & 0 & 0 \\
\hline $\mathrm{a}_{1}$ & Environmental temperature rise & 43200 & 43320 & 120 \\
\hline $\mathrm{a}_{2}$ & Appearance of a strong wind & 43200 & 43200 & 0 \\
\hline $\mathrm{a}_{3}$ & Formation of thunderstorm & 43200 & 43499.98 & 299.98 \\
\hline $\mathrm{a}_{4}$ & Vibration of wires due to strong wind & 43380 & 43380 & 0 \\
\hline $\mathrm{a}_{5}$ & $\begin{array}{l}\text { Overlapping wires on surrounding } \\
\text { objects due to strong wind }\end{array}$ & 43201 & 43440 & 239 \\
\hline $\mathrm{a}_{6}$ & $\begin{array}{l}\text { Falling tree and breaking off tree } \\
\text { branches due to strong wind }\end{array}$ & 43201 & 43499 & 298 \\
\hline $\mathrm{a}_{7}$ & $\begin{array}{l}\text { Lightning, atmospheric overvoltage } \\
\text { due to thunderstorm }\end{array}$ & 43200 & 43499.98 & 299.98 \\
\hline $\mathrm{a}_{8}$ & $\begin{array}{l}\text { The weakening and / or violation of } \\
\text { the mechanical strength of the } \\
\text { supports, wires, insulators due to the } \\
\text { influence of the meteorological factor }\end{array}$ & 43500 & 43500 & 0 \\
\hline $\mathrm{a}_{9}$ & $\begin{array}{l}\text { Drop of support / wire break due to } \\
\text { weakening and / or violation of the } \\
\text { mechanical strength of supports, wires }\end{array}$ & 43501 & 43501 & 0 \\
\hline $\mathrm{a}_{10}$ & $\begin{array}{l}\text { Short circuit due to weakening and / } \\
\text { or violation of mechanical strength of } \\
\text { supports, wires, insulators }\end{array}$ & 43500 & 43501 & 1 \\
\hline $\begin{array}{l}\text { Failure of electric power system (the } \\
\text { outage of the electric power supply to } \\
\text { consumers, the appearance of a } \\
\text { danger zone for humans) }\end{array}$ & 43502 & 43502 & 0 \\
\hline
\end{tabular}

It is necessary to determine the critical path for the process of manifestation of the threats caused by the influence of meteorological factors. The critical path of the manifestation of the problem passing through the chain of events $\mathrm{a}_{0} \rightarrow \mathrm{a}_{2} \rightarrow \mathrm{a}_{4} \rightarrow \mathrm{a}_{8} \rightarrow \mathrm{a}_{9} \rightarrow \mathrm{a}_{11}$ is $\Delta t_{P M}=$ $43502 \mathrm{~min} .=30.2$ days. Thus, $\lambda=0.03$ problems per day.

To identify the above threats, DM uses GIS. Based on the results obtained, it is necessary to forecast the occurrence of an undesirable event (increase / decrease in temperature, the formation of thunderstorms, etc.).

Fig. 4 shows a network model of the identification of a problem caused by the influence of meteorological factors during the operation of electric power networks (the name of the transition is stamped over the line, the transition duration in minutes is indicated at the bottom of the line). 


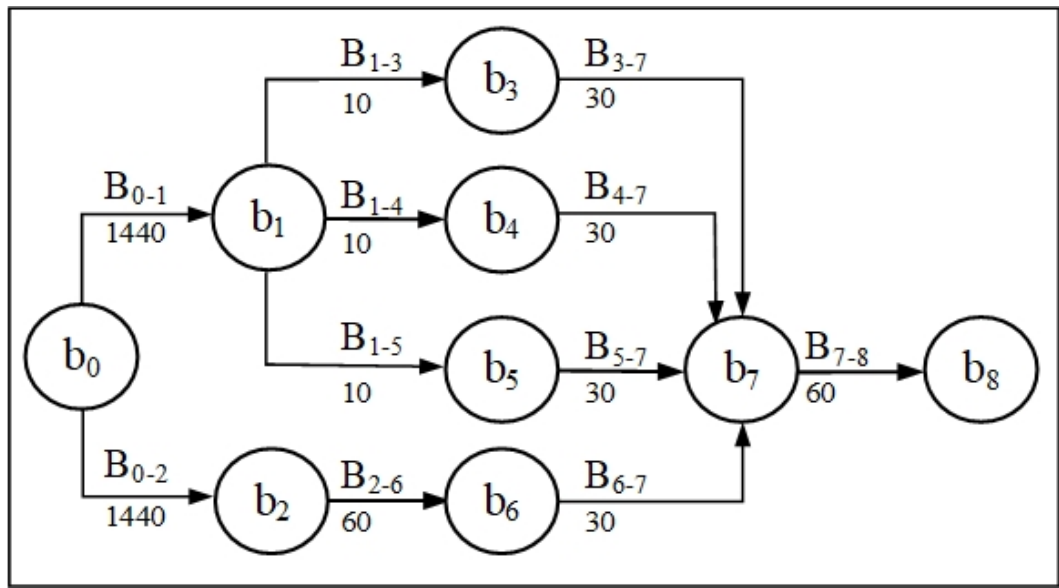

Fig. 4. Network model of the identification of a problem caused by the impact of meteorological factors during the operation of electric power system.

In the table 2 the list of events of the network model of the process of the identification of the problem are shown, indicating their earliest possible time, the latest acceptable time, and time reserve.

Table 2. Events on the identification of the problems caused by the impact of meteorological factors during the operation of electric power network.

\begin{tabular}{|c|c|c|c|c|}
\hline $\begin{array}{c}\text { Designations } \\
\text { of events }\end{array}$ & $\begin{array}{c}\text { Name of the } i \text { th event of the process of } \\
\text { manifestation of the problem }\end{array}$ & $T_{P}(j)$ & $T_{A}(i)$ & $R_{i}$ \\
\hline $\mathrm{b}_{0}$ & $\begin{array}{l}\text { Startup of monitoring meteorological } \\
\text { conditions }\end{array}$ & 0 & 0 & 0 \\
\hline $\mathrm{b}_{1}$ & $\begin{array}{l}\text { Monitoring (forecast) meteorological } \\
\text { conditions (temperature, wind speed) }\end{array}$ & 1440 & 1490 & 50 \\
\hline $\mathrm{b}_{2}$ & $\begin{array}{l}\text { Monitoring of the adjacent territory (for the } \\
\text { presence of overgrown shrubs and trees in the } \\
\text { protective zone of the electric power } \\
\text { transmission line) }\end{array}$ & 1440 & 1440 & 0 \\
\hline $\mathrm{b}_{3}$ & Detecting environmental temperature rise & 1450 & 1500 & 50 \\
\hline $\mathrm{b}_{4}$ & Detecting of an increase in wind speed & 1450 & 1500 & 50 \\
\hline $\mathrm{b}_{5}$ & Detecting the formation of thunderclouds & 1450 & 1500 & 50 \\
\hline $\mathrm{b}_{6}$ & $\begin{array}{l}\text { Recording a violation of the protective zone of } \\
\text { the electric power transmission line (the } \\
\text { presence of a forest) }\end{array}$ & 1500 & 1500 & 0 \\
\hline $\mathrm{b}_{7}$ & Analysis of the results & 1530 & 1530 & 0 \\
\hline $\mathrm{b}_{8}$ & $\begin{array}{l}\text { Preparation of a report indicating the maximum } \\
\text { credible accident }\end{array}$ & 1590 & 1590 & 0 \\
\hline
\end{tabular}

It is necessary to determine the critical path for the process of identification of the threats caused by the influence of meteorological factors. The critical path of the identification of the problem passing through the chain of events $\mathrm{b}_{0} \rightarrow \mathrm{b}_{2} \rightarrow \mathrm{b}_{6} \rightarrow \mathrm{b}_{7} \rightarrow \mathrm{b}_{8}$ is $\Delta t_{P I}=1590$ min. $=1.1$ days. Thus, $v_{1}=0.91$ identifications per day.

After identifying possible threats, the DM takes appropriate preventive measures to neutralize the threats. 
Figure 5 shows a network model of the neutralization of a problem caused by the influence of meteorological factors during the operation of electric power networks (the name of the transition is stamped over the line, the transition duration in minutes is indicated at the bottom of the line).

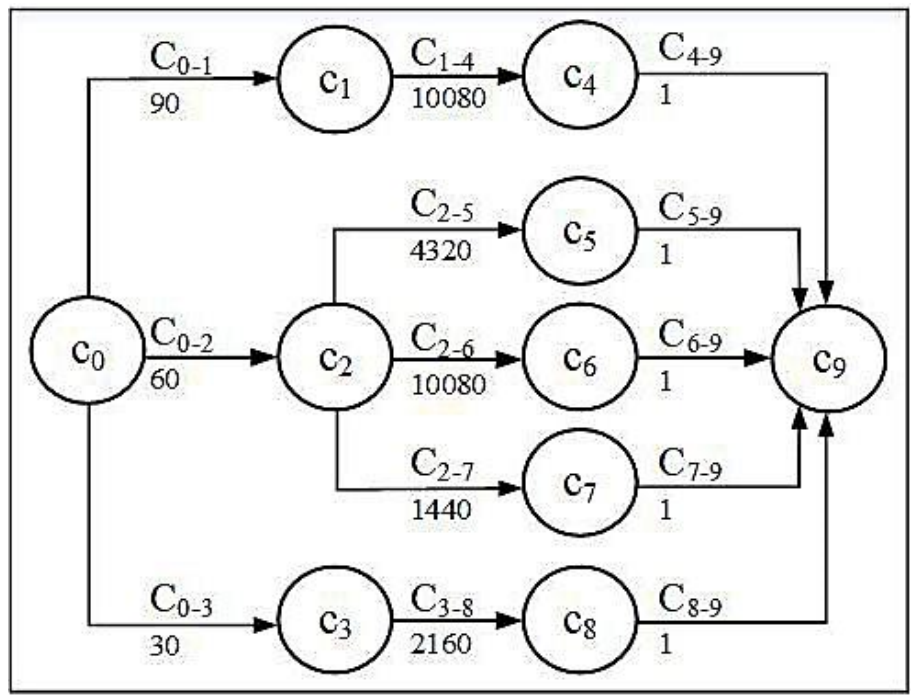

Fig. 5. Network model of the neutralization of a problem caused by the impact of meteorological factors during the operation of electric power system.

In the table 3 the list of events of the network model of the process of the neutralization of the problem are shown, indicating their earliest possible time, the latest acceptable time, and time reserve.

Table 3. Events on the neutralization of the problems caused by the impact of meteorological factors during the operation of electric power network.

\begin{tabular}{|c|l|c|c|c|}
\hline $\begin{array}{c}\text { Designations } \\
\text { of events }\end{array}$ & \multicolumn{1}{|c|}{$\begin{array}{c}\text { Name of the } i \text {-th event of the process of } \\
\text { neutralization of the problem }\end{array}$} & $T_{P}(j)$ & $T_{A}(i)$ & $R_{i}$ \\
\hline$c_{0}$ & The analysis of the report & 0 & 0 & 0 \\
\hline$c_{1}$ & $\begin{array}{l}\text { Solutions to address the risks associated with } \\
\text { an increase in environmental temperature are } \\
\text { identified }\end{array}$ & 90 & 90 & 0 \\
\hline$c_{2}$ & $\begin{array}{l}\text { Solutions to address wind hazards are } \\
\text { identified }\end{array}$ & 60 & 90 & 30 \\
\hline$c_{3}$ & $\begin{array}{l}\text { Solutions to address thunderstorm-related } \\
\text { threats are identified }\end{array}$ & 30 & 8010 & 7980 \\
\hline$c_{4}$ & $\begin{array}{l}\text { Standard electric wire is replaced with high } \\
\text { temperature electric wire }\end{array}$ & 10170 & 10170 & 0 \\
\hline$c_{5}$ & Vibration dampers are installed & 4380 & 10170 & 5790 \\
\hline$c_{6}$ & $\begin{array}{l}\text { Supports are installed with a large spacing of } \\
\text { wires vertically, with increased horizontal } \\
\text { displacement of wires of different tiers }\end{array}$ & 10140 & 10170 & 30 \\
\hline$c_{7}$ & $\begin{array}{l}\text { Shrubs and trees in the protective zone of the } \\
\text { electric power transmission line are cut down }\end{array}$ & 1500 & 10170 & 8670 \\
\hline $\mathrm{c}_{8}$ & Cable lightning rods are installed & 2190 & 10170 & 7980 \\
\hline $\mathrm{c}_{9}$ & Threat neutralization & 10171 & 10171 & 0 \\
\hline
\end{tabular}


It is necessary to determine the critical path for the process of neutralization of the threats caused by the influence of meteorological factors. The critical path of the neutralization of the problem passing through the chain of events $\mathrm{c}_{0} \rightarrow \mathrm{c}_{1} \rightarrow \mathrm{c}_{4} \rightarrow \mathrm{c}_{9}$ is $\Delta t_{P N}=10171 \mathrm{~min} .=$ 7.1 days. Thus, $v_{2}=0.14$ neutralizations per day.

In a detailed study of the events of the process of neutralization of the threat caused by the impact of meteorological factors, it can be noted that their implementation is periodic, and with subsequent occurrence of such problems, preventive actions are temporarily not required. For example, the installation of lightning rods will again be required only if the already installed ones are destroyed.

Thus, the following values are obtained: $\lambda=0.03 ; v_{1}=0.91 ; v_{2}=0.14 ; \zeta^{+}=1 / 30=$ $0.03 ; \zeta^{-}=0.1 \zeta^{+}=0.003$. The performance indicator $P_{I N P}$ is 0.94 .

\section{Discussion}

As a result of the study, the safety management technology of electric power networks based on the use of GIS was developed. The research considers threats caused by the impact of meteorological factors. In particular, some problems arising under the influence on the control object of environmental temperature, wind, and thunderstorm were analyzed. The performance indicator of the safety management system of electric power system for the case under consideration is determined ( $\left.P_{I N P}=0.94\right)$.

It was established that the following equation (7) should be fulfilled in safety management:

$$
\frac{v_{1}+v_{2}}{\lambda}>1
$$

\section{Conclusion}

The presented simulation of safety management processes allows to guarantee reliable and safe electric power supply to consumers. Thus, one of the fundamental aspects of sustainable development has been realized. In further studies, it is planned to consider additional factors affecting the performance indicator of the safety management system of electric power networks.

\section{Acknowledgments}

The reported study was funded by RFBR, project number 20-38-90225.

\section{References}

1. Y. Wang, X. Gao, Y. Cai, M. Yang, S. Li, Y. Li, Reliability evaluation for aviation electric power system in consideration of uncertainty, Energies, 13(5), (2020) DOI:10.3390/en13051175.

2. V. Mankov, S. Efremov, V. Monashkov, Grounding device for electrical networks and electrical installations in the arctic regions, 4th International Scientific Conference on Arctic: History and Modernity. Institute of Physics Publishing, Bristol (2019 DOI: 10.1088/1755-1315/302/1/012066

3. J. Zhang, D. Wang, F. Su, X. Han, X. Jin and et al., Design and application research of an power grid safety supervision and management business integrated platform based 
on Sotower3.0, Procedia Computer Science, 131, 676-682 (2018) DOI: 10.1016/j.procs.2018.04.311

4. O. John, C. Lehmköster, C. Rehtanz, Financially optimal decisions of electricity network operators under regulatory uncertainty, CIGRE 2011 Bologna Symposium The Electric Power System of the Future: Integrating Supergrids and Microgrids, Bologna (2011)

5. V. Evangelopoulos, I. Avramidis, P. Georgilakis, Flexibility services management under uncertainties for power distribution systems: Stochastic scheduling and predictive real time dispatch, IEEE, 8, 38855-38871 (2020) DOI: 10.1109/ACCESS.2020.2975663

6. N. Kaneko, Y. Fujimoto, S. Kabe, M. Hayashida, Y. Hayashi, Sparse modeling approach for identifying the dominant factors affecting situation-dependent hourly electricity demand, Applied Energy, 265 (2020) DOI: 10.1016/j.apenergy.2020.114752

7. I. Skvortsova, R. Latyshev, Y. Truntsevsky, Management of investment activities in the field of energy saving, 2018 International Science Conference on Business Technologies for Sustainable Urban Development, EDP Sciences, Les Ulis (2019) DOI: 10.1051/e3sconf/201911002063

8. I. Kalogeropoulos, H. Sarimveis, Predictive control algorithms for congestion management in electric power distribution grids, Applied Mathematical Modelling 77, 635-651 (2020) DOI: 10.1016/j.apm.2019.07.034

9. V. Manusov, S. Kokin, J. Ahyoev, Multi-criteria analysis of fuzzy symptoms of electrical faults in power systems, International Journal of Energy Production and Management, 3(2), 89-96 (2018) DOI: 10.2495/EQ-V3-N2-89-96

10. N. Rumyantseva, E. Primak, A. Uljanov, V. Kiss. Assessment of an occupational risk using injury safety indicators, International Scientific-Practical Conference on Quality Management and Reliability of Technical Systems. Institute of Physics Publishing, Bristol (2019) DOI: 10.1088/1757-899X/666/1/012090

11. A. Semeykin, E. Klimova, I. Kochetkova, Forecasting and managing professional risks using information-analytical systems based on fuzzy logic methods, 2019 International Science and Technology Conference on Earth Science, ISTCEarthScience 2019, Institute of Physics Publishing, Bristol (2020) DOI: 10.1088/1755-1315/459/5/052083

12. O. Filatova, Y. Bashkatova, D. Filatova, L. Ilyashenko, Human organism in the conditions of homeostatic dynamics of meteoroligical parameters of the russian north, Ekologiya Cheloveka (Human Ecology) 9, 24-30 (2019) DOI: 10.33396/1728-08692019-9-24-30

13. F. Bryukhan, I. Lavrusevich, A. Vinogradov, I. Vinogradov, Consideration of external natural impacts in the design of hazardous production facilities, 6th International Scientific Conference on Integration, Partnership and Innovation in Construction Science and Education, IPICSE 2018. EDP Sciences, Les Ulis (2018) DOI: 10.1051/matecconf/201825106001

14. J. Bartok, O. Habala, P. Bednar, M. Gazak, L. Hluchý, Data mining and integration for predicting significant meteorological phenomena, International Conference on Computational Science, ICCS 2010. Elsevier B.V., Amsterdam (2010)

15. M. Matouqa, T. El-Hasan, H. Al-Bilbisi, M. Abdelhadi, M. Hindiyeh, S. Eslamian, S. Duheisat, The climate change implication on Jordan: A case study using GIS and Artificial Neural Networks for weather forecasting, Journal of Taibah University for Science, 7, 44-55 (2013) DOI: 10.1016/j.jtusci.2013.04.001

16. S. Wang, Y. Zhong, E. Wang, An integrated GIS platform architecture for spatiotemporal big data, Future Generation Computer Systems, 94, 160-172 (2019) DOI: $10.1016 /$ j.future.2018.10.034

17. F. D'Amico, A. Calvi, E. Schiattarella, M. Prete, V. Veraldi, BIM and GIS data 
integration: a novel approach of technical/environmental decision-making process in transport infrastructure design, 2019 Transport Infrastructure and Systems in a Changing World. Towards a more Sustainable, Reliable and Smarter Mobility, TIS Roma 2019. Elsevier B.V., Amsterdam (2020) DOI: 10.1016/j.trpro.2020.02.090

18. R. Satria, M. Castro, GIS tools for analyzing accidents and road design: a review, XII Conference on Transport Engineering, CIT 2016, Elsevier B.V., Amsterdam (2016), DOI: $10.1016 /$ j.trpro.2016.12.033

19.Z. Ma, Y. Ren, Integrated application of BIM and GIS: an overview, Creative Construction Conference, CCC 2017, Elsevier Ltd, Amsterdam (2017), DOI: 10.1016/j.proeng.2017.08.064

20. V. Burlov, A. Andreev, F. Gomazov, Mathematical model of human decision - A methodological basis for the realization of the human factor in safety management, 9th Annual International Conference on Biologically Inspired Cognitive Architectures, BICA 2018. Elsevier B.V., Amsterdam (2018) DOI: 10.1016/j.procs.2018.11.018

21. M. Borisova, A. Byzov, S. Efremov, Assessment of the maximum possible number of victims of accidents at hazardous production facilities for insurance purposes, International Scientific-Practical Conference on Quality Management and Reliability of Technical Systems 2019. Institute of Physics Publishing, Bristol (2019) DOI: 10.1088/1757-899X/666/1/012096

22. G. Correa-Henao, J. Yusta, R. Lacal-Arántegui, Using interconnected risk maps to assess the threats faced by electricity infrastructures, International Journal of Critical Infrastructure Protection, 6, 197-216 (2013) DOI: 10.1016/j.ijcip.2013.10.002

23. M. Polyukhovich, V. Burlov, V. Mankov, A. Bekbayev, Electric power supply management of the construction site in the interests of facilitating electrical safety, 2019 International Scientific Conference on Energy, Environmental and Construction Engineering, EECE 2019, EDP Sciences, Les Ulis (2019) DOI: $10.1051 / \mathrm{e} 3$ sconf/201914008006 